\title{
Effectiveness of Instruction Program on Nurses' Knowledgeabout Clinical Devices Alarm in Intensive Care Unit
}

\author{
ALI S. OBEID,MSCN ${ }^{1}$, HUDABAKERHASSAN ${ }^{2}$ \\ (Academic Nurse Specialist, Ministry of Health) \\ (Prof, Adult Nursing Department, College of Nursing-University of Baghdad) ${ }^{2}$ \\ Corresponding author: Academic Nurse Specialist: Ali S. Obeid., E-mail: alshaibaniali89@gmail.com
}

\begin{abstract}
The clinical alarms are used to enhance safety by alerting care provider to any deviations from normal status. The alarms alert care provider when there is deterioration in patient's condition and there is a need for intervention, or when a device is not working as it should ${ }^{(1)}$.

Objectives:The aims of present study is to find out the effectiveness of instruction program on nurses knowledge about the clinical devices alarm, and to find out the relationship between the effectiveness of program and nurses level of education, year of experiences in nursing, and year of experiences in intensive care units.

Methodology: a quasi-experimental study wascarried out on 80 nurses is divided to two groups (Experimental group who exposed on program, and control group to compare with experimental group) two group of nurse is workingin Al-Imam Al-Hussein Medical City, in holy Kerbala'a City, Iraq. The study started at $3^{\text {rd }}$ of May, 2020 to $25^{\text {th }}$ of May, 2021. The instrument consist of two part; part one deals the characteristics of the sample which of age, gender, level of education, year of experiences in nursing, year of experiences in intensive care units, and specific training course. Part two deals the nurses knowledge related to clinical devices alarm which of 30 items, the validity of instrument and program was obtained from 12 expert in specialty, the reliability was $=1.81$, the data analysis was done by uses SPSS program version 23, the statistical methods which used in present study is descriptive and inferential statistics.

Results: the findings of present study revealed that the correct answer for experimental group at pretest was $42.44 \%$ then at post test was $99.87 \%$, and correct answer for control group was 31.71 at pretest and $35.69 \%$ at post test., and there were statistical differences between experimental and control group at post test at $\mathrm{P} \leq 0.05$ Conclusions:the study concluded that the instruction program on nurses knowledge was effective on experimental group through improving their knowledge

Recommendations:The researchers recommend that the current program should be applied to all nurses in critical units because of its utmost importance in monitoring and patient safety.

Keywords:Effectiveness, InstructionsProgram,Nurses, Knowledge, Clinical, Monitoring, Devices, Alarms, Intensive Care Unit
\end{abstract}

\section{INTRODUCTION}

Clinical alarms warn caregivers of immediate or potential adverse patient conditions. Alarms and their shortcomings have been the topic of numerous studies and analysis (2). Historically, the word 'alarm' originates from the Latin, 'ad arma', or the French, 'à l'arme', which can be translated into 'to your weapons'. Hence, the word indicates a call for immediate action, for attack or for defense (3). Every day, caregivers/nurses are bombarded by a myriad of alarms. These beeps, chimes, bells and horns become white noise to nurses resulting in slow or non-existent responses. Many nurses have become not attentive to these alarms due to the large number of false or no actionable alarms (4) (5). Technologic advances in hospitals have increased substantially over the past 25 years. With these advances come sophisticated and complicated monitoring equipment, many of which are manufactured with built-in audible alarms. These alarms are intended to alert the clinician and nurses regarding a deviation from a predetermined "normal" status and are considered to be a key tool to improving the safety of patients by communicating information that requires a response or awareness by the operator (6). With the development of medical technology, clinical alarms from diverse medical devices, which are explosively increasing, are becoming a new issue in intensive care units. Medical device (clinical) alarms, which were designed to draw medical staff's attention when a patient's conditions goes beyond the proper range, are causing a new alarm hazard problem (7).

\section{METHODOLOGY}

Design of the Study: a quasi-experimental design (testretest method) is used to conduct the present study

Ethical Consideration: The researcher obtained the approval of the hospital administration, as well as the consent of the participants in the research.

Setting of the Study: Al-Imam Al-Hussein Medical City, Holy Karbala, Iraq

The Sample of the Study:A purposive, non-probability sample of (80) nurses who work at the intensive care unit, and medical. The sample was divided to two groups which of (40) nurses as experimental, 40 nurses as control group. Instrument: the instrument consist two part; part one deals the characteristics of the study sample which of 6 items, and part two consist of 30 items constructed according to review of literature

Validity of Instrument: the validity of instrument was obtained through 12 experts

Reliability of instrument: the reliability was estimated by using Cronbach's Alpha which equal 0.83 
Statistical and Data Analysis:the researchers are used Package of Social Sciences version 23, and used Descriptive, and Inferential Statistical for data analysis

\section{RESULTS}

The socio-demographic characteristics of present study in table (1) revealed that the age of experimental group was $55 \%$ at $18-24$ years old, and the control group was $40 \%$ at 25-34 years old, high percent of nurses who participated in present study was females which of $57 \%$ for experimental, and $50 \%$ for control group, high percent of both group was graduated from nursing college which of $50 \%, 70 \%$ of experimental and control group have 1-5 year of experiences in nursing which of $70 \%$, high percent of experimental and control group have 1-3 year of experiences in critical care unit which of $65 \%$, and $62.5 \%$ respectively, and majority of the nurses not have training course related to clinical alarm which of $90 \%$, and $75 \%$ for experimental, and control group respectively.

Table 2 presented the nurses responses about clinical devices alarms for experimental, and control group at pre and post-test which revealed that the correct answer for experimental group at pretest was $42.44 \%$ then at post test was $99.87 \%$, while the correct answer for control group was 31.71 at pretest and $35.69 \%$ at post test.

Table 1: Distribution of the Study Sample (Experimental, and control groups) according to their Socio demographic Characteristics $(\mathrm{n}=40)$

\begin{tabular}{|c|c|c|c|c|c|c|}
\hline \multirow{2}{*}{ No. } & \multirow{2}{*}{\multicolumn{2}{|c|}{ Characteristics }} & \multicolumn{2}{|c|}{ Experimental group } & \multicolumn{2}{|c|}{ Control group } \\
\hline & & & Freq. & $\%$ & Freq. & $\%$ \\
\hline \multirow[t]{6}{*}{1} & \multirow[t]{6}{*}{ Age/Years } & $18-24$ & 22 & 55.0 & 15 & 37.5 \\
\hline & & $25-34$ & 16 & 40.0 & 16 & 40.0 \\
\hline & & $35-44$ & 1 & 2.5 & 5 & 12.5 \\
\hline & & $45-54$ & 1 & 2.5 & 3 & 7.5 \\
\hline & & 55 and over & 0 & 0 & 1 & 2.5 \\
\hline & & Mean \pm SD & & & & \\
\hline \multirow[t]{2}{*}{2} & \multirow[t]{2}{*}{ Gender: } & Male & 17 & 42.5 & 20 & 50.0 \\
\hline & & Female & 23 & 57.5 & 20 & 50.0 \\
\hline \multirow[t]{3}{*}{3} & \multirow{3}{*}{ Level of education } & College & 20 & 50.0 & 20 & 50.0 \\
\hline & & Institute & 9 & 22.5 & 9 & 22.5 \\
\hline & & Preparatory & 11 & 27.5 & 11 & 27.5 \\
\hline \multirow[t]{4}{*}{4} & \multirow{4}{*}{$\begin{array}{l}\text { Years of experience } \\
\text { In nursing }\end{array}$} & $1-5$ & 28 & 70.0 & 28 & 70.0 \\
\hline & & $6-10$ & 5 & 12.5 & 5 & 12.5 \\
\hline & & $11-15$ & 3 & 7.5 & 3 & 7.5 \\
\hline & & $16 \leq$ & 4 & 10.0 & 4 & 10.0 \\
\hline \multirow[t]{2}{*}{5} & \multirow{2}{*}{ Years of experience in ICU } & $1-3$ years & 26 & 65.0 & 25 & 62.5 \\
\hline & & 4-6 years & 14 & 35.0 & 15 & 37.5 \\
\hline \multirow[t]{2}{*}{6} & \multirow{2}{*}{ Specific Training course } & No & 36 & 90.0 & 30 & 75.0 \\
\hline & & Yes & 4 & 10.0 & 10 & 25.0 \\
\hline
\end{tabular}

Similarity for two variables for Experimental and control group No: Number, F: Frequency, \%: Percentage

Table 2: Nurses Responses for clinical devices alarmsfor experimental and Control Group

\begin{tabular}{|c|c|c|c|c|c|c|c|c|}
\hline \multirow{3}{*}{$\begin{array}{l}\text { Nltems Knowledge of } \\
\text { clinical devices alarms }\end{array}$} & \multicolumn{4}{|c|}{ Experimental group $(\mathrm{N}=40)$} & \multicolumn{4}{|c|}{ Control group $(\mathrm{N}=40)$} \\
\hline & \multicolumn{2}{|c|}{ Pre-test } & \multicolumn{2}{|c|}{ Post-test } & \multicolumn{2}{|c|}{ Pre-test } & \multicolumn{2}{|c|}{ Post-test } \\
\hline & Correct & Incorrect & Correct & Incorrect & Correct & Incorrect & Correct & Incorrect \\
\hline Total & $42.44 \%$ & $57.56 \%$ & $99.87 \%$ & $0.13 \%$ & $31.71 \%$ & $68.29 \%$ & $35.69 \%$ & $64.31 \%$ \\
\hline
\end{tabular}

Table 3: Statistical Differences between pre and posttest of instruct program for Experimental group

\begin{tabular}{|l|l|l|l|l|l||}
\hline knowledge about clinical Alarms & M.S & S.D & t.test & df & $\begin{array}{l}\text { Sig. } \\
\text { P } \leq 0.05\end{array}$ \\
\hline Pretest & 0.470 & 2.973 & 0.236 & 39 & $\begin{array}{l}0.143 \\
\text { N.S. }\end{array}$ \\
\hline Posttest & 0.025 & 0.158 & 36.296 & 39 & $\begin{array}{l}0.000 \\
\text { H.S. }\end{array}$ \\
\hline
\end{tabular}

Table 3: presented the effectiveness of instruction program on experimental group, which revealed that there were highly significant between pre andpost programon nurses knowledge related to general information about alarmat $P \leq 0.05$

Table 4: shows that there were highly significant between the experimental and control group regarding to nurses knowledge about the alarm at $\mathbf{P} \leq \mathbf{0 . 0 5}$ level

\begin{tabular}{|l|l|l|l|l|l|l|l|}
\hline & & & & $95 \%$ Confidence Interval of the Difference & & \\
\hline Items & M.S & S.D & Std. Error Mean & Lower & Upper & & \\
\hline $\begin{array}{l}\text { Nurses } \\
\text { knowledge about } \\
\text { alarm }\end{array}$ & -28.9750 & 8.11926 & 1.28377 & -31.57167 & -26.37833 & -22.570 & 39 \\
\hline
\end{tabular}


Figure 1: Pre and posttest for Experimental and control group for clinical monitoring devices alarms knowledge

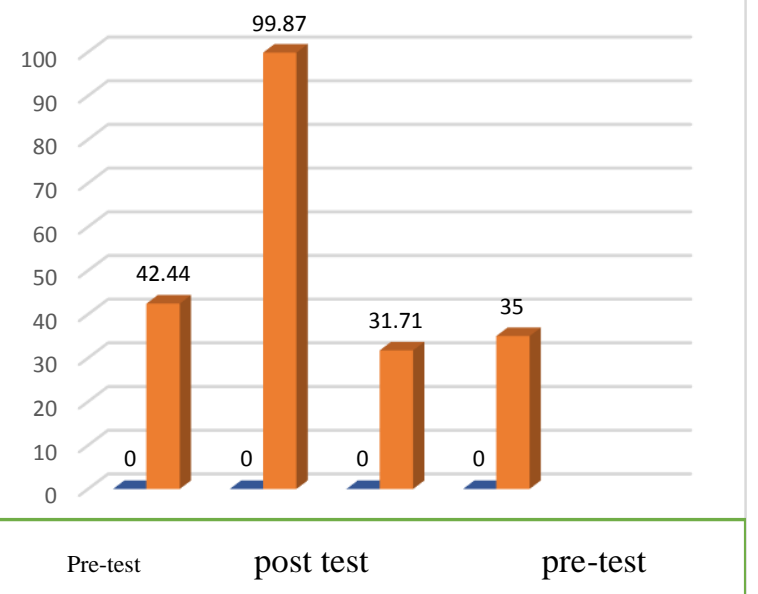

Figure 4-1: shows the improvement of Experimental group knowledge at posttest after implementation of program while the control group still at the same level.

Table 3 revealed that there were relationship between the effectiveness of instruction program and nurses' year of experiences in nursing at $p \leq 0.0$ level

\section{DISCUSSION}

Regarding socio-demographic characteristics which are presented in table 1 showed the eligible sample for this study consisted of 80 adult nurse for both two groups (study versus control). Thirty seven (37) nurses were males and forty three (43) were female nurses. The current outcome can be similarto a research was conducted by researcherswho stated that the results of the study in both groups were based on demographic characteristics such as age, gender, level of education, years of experience, years of experience in intensive care unit and participation in clinical alarm course. There was no significant difference at $(p>0.05)$ between the two groups related to the variables mentioned $^{8}$. Our age findings are similar to the results of a survey design study that was conducted by Rachel et al to evaluate nurses' perceptions of infusion pump alarms in Bethlehem, Pennsylvania, USA. The majority of participants wereof30-40 years of age ${ }^{9}$.

According to current findings of study which showed a descriptive assessment of clinical alarms questionnaire for both study and control groups before applying the interventional program to assess studied samples' knowledge and practices regarding clinical monitoring devices alarms (table 2). Results of the study found that nurses knowledge before applying program were at moderate levels for bothstudy and control group. Respectively as regard to before implementation of the program. Safaa, and colleaguescarried out a quasiexperimental design study in Egypt to deliver interventional program for (20) adult men patient in intensive care unit. Before giving the interventions, they assessed the targeted sample's knowledge level concerning clinical alarm. The results indicated that most study participants were confirmed to have poor to moderate level of knowledge related to clinical alarms. And after the implementation of the interventional program, nurses' knowledge improved. So, these results come in total agreement with the current results of the study ${ }^{10}$.

Effectiveness of the interventional program is clearly observed through the results of Table 3 . This table illustrates that there are significant mean differences concerning specific knowledge areas between the study and control groups after applying the program in the posttest period at $p$ value $\leq 0.01$. These findings were agreed with outcomes obtained from educational study conducted by Thompson and Stapley, in University of York, in UK to identify whetherthe educational interventions improve nurses' clinical decision making and judgement. They emphasized that the educational program helps to improve and develop the skills and knowledge of nurses and found wide differences between pre-post-tests ${ }^{11}$.

\section{CONCLUSIONS}

In conclusion, the results of the current study show that the study group participants have significant improvement in post-test knowledge scores about clinical monitoring devices alarms causes, recurrence, errors, control and solutions. The study recommended to encourage nurses staffat Al-Imam Al-Hussein Medical City in Holy Kerbala'a Governorate to perform clinical alarms management courses periodically.

Acknowledgements: This research was funded by Authors. Moreover, we would like to thank the study participants and data collectors for their fully participation and responsible data collection.

Conflict of interest: None declared.

Ethical approval: The study was approved by the Institutional Ethics Committee.

\section{REFERENCES}

1. Solet, J. M. and P. R. Barach."Managing alarm fatigue in cardiac care." Progress in Pediatric Cardiology. 2012. Vol.33 (1). 85-90.

2. Maria Cvach, Deborah Dang, Jan Foster, and Janice Irechukwu. Enhancing patient safety through improved surveillance. Clinical Alarms and the Impact on Patient Safety. Initiatives in safe patient care. Medical University of South Carolina 2009.p.p: 1, 3, 5, 6

3. Tsunami Alarm System. http://www.tsunami-alarm system.com Accessed Oct 2012. P.13.

4. Cvach, M. "Monitor alarm fatigue: an integrative review." Biomedical Instrumentation \& Technology. (2012). Vol. 46(4): 268-277.

5. Rashotte J., Alarm Management: A quality Improvement Project to Decreased Non-actionable Cardiac Telemetry Alarms. Research review. Dynamics. 2013; 24 (4):42-43.

6. Drew BJ, Califf RM, Funk M, el al. Practice standards for electrocardiographic monitoring in hospital settings. Circulation. 2004;110:2721-2746.

7. Borowski M, Gorges M, Fried R, Such O, Wrede C, Imhoff M. Medical device alarms. Biomed Tech (Berl) 2011;56(2):73-83.

8. Min Cho, Hwasoon Kim, YoungWhee Lee and Insook Cho, Clinical Alarms in Intensive Care Units: Perceived Obstacles of Alarm Management and Alarm Fatigue in Nurses. Department of Nursing, Inha University, Incheon, Korea.2021. p.1, 50 
9. Rachel R. Vitoux, Catherine Schuster and Kevin R. Glover Perceptions of Infusion Pump Alarms. Insights Gained From Critical Care Nurses. B. Braun Medical, Bethlehem, Pennsylvania. Published by Wolters Kluwer Health, Inc. on behalf of the Infusion Nurses Society. The Art and Science of Infusion Nursing Journal.USA.2018. p.p: 309, 310, 311, 316.

10. Safaa E. Sayed Ahmed and Zeinab M. ShabanAysha. The Effect of Implementing Clinical Alarm Nursing Intervention Program on Nurses' Knowledge, Practice and Patient outcomes at Intensive Care Unit. A published thesis. Journal of Nursing and Health Science (IOSR-JNHS). e-ISSN: 2320 1959.p- ISSN: 2320-1940 Volume 8, Issue 4 Ser. I. (2019), p.p: $01-14$

11. Thompson $C$ and Stapley S. Do educational interventions improve nurses' clinical decision making and judgment. A systematic review, International Journal of Nursing Studies, 2011 ; 48(7): 881-893 